\title{
MATHEMATICAL OPTIMIZATION: APPLICATION TO THE DESIGN OF OPTIMAL MICRO-CHANNEL HEAT SINKS
}

\begin{abstract}
F. U. Ighalo ${ }^{a}$,
T. Bello-Ochende ${ }^{\mathrm{a}}$, and J. P. Meyer ${ }^{\mathrm{a}}$

${ }^{\mathrm{a}}$ University of Pretoria

Department of Mechanical and Aeronautical

Engineering

Pretoria, 0002, South Africa

tbochende@up.ac.za

\section{ABSTRACT}

This paper documents the geometrical optimization of a micro-channel heat sink embedded inside a highly conductive solid, with the intent of developing optimal solutions for thermal management in microelectronic devices. The objective is to minimize the peak wall temperature of the heat sink subject to various constraints such as manufacturing restraints, fixed pressure drop and total fixed volume. A gradient based multi-variable optimization algorithm is used as it adequately handles the numerical objective function obtained from the computational fluid dynamics simulation. Optimal geometric parameters defining the micro-channel were obtained for a pressure drop ranging from $10 \mathrm{kPa}$ to $60 \mathrm{kPa}$ corresponding to a dimensionless pressure drop of $6.5 \times 10^{7}$ to $4 \times 10^{8}$ for fixed volumes ranging from $0.7 \mathrm{~mm}^{3}$ of $0.9 \mathrm{~mm}^{3}$. The effect of pressure drop on the aspect ratio, solid volume fraction, channel hydraulic diameter and the minimized peak temperature are reported. Results also show that as the dimensionless pressure drop increases the maximised dimensionless global thermal conductance also increases. These results are in agreement with previous work found in literature.

Keywords: micro-channel, geometric optimization, thermal conductance, gradient based algorithm
\end{abstract}

\section{NOMENCLATURE}

A channel cross-sectional area, $\mathrm{m}^{2}$

B channel width, $m$

$\mathrm{Be} \quad$ Bejan number

C global thermal conductance

$\mathrm{C}_{\mathrm{p}} \quad$ specific heat capacity, $\mathrm{J} / \mathrm{kg}$

D diameter, $m$

$\mathrm{f}(\mathbf{x})$ objective function

$\mathrm{g}_{\mathrm{i}}(\mathbf{x})$ i-th inequality constraint function

$\mathrm{G}$ computational domain width, $\mathrm{m}$

$h_{j}(\mathbf{x}) \quad j$-th equality constraint function

$\mathrm{H}$ computational domain height, $\mathrm{m}$

$\mathrm{k}$ thermal conductivity, $\mathrm{W} /(\mathrm{m} . \mathrm{K})$

L channel axial length, $\mathrm{m}$

$\mathrm{Nu}$ Nusselt number

$\mathrm{P}$ pressure, $\mathrm{Pa}$

$\mathrm{P}[\mathrm{k}] \quad$ successive sub-problem

q" Heat flux, $W / \mathrm{m}^{2}$

$i^{n} \quad$ n-dimensional real space

$\mathrm{T}$ temperature, $\mathrm{K}$

$t_{1} \quad$ half thickness of vertical solid, $m$

$\mathrm{t}_{2} \quad$ channel base thickness, $\mathrm{m}$

$t_{3}$ channel base to height distance, $m$

$\mathrm{U}$ velocity, $\mathrm{m} / \mathrm{s}$

$\mathrm{V} \quad$ Volume, $\mathrm{m}^{3}$

W heat sink width, $\mathrm{m}$

$\mathrm{x}, \mathrm{y}, \mathrm{z}$ cartesian coordinates, $\mathrm{m}$

\section{Greek symbols}

$\alpha \quad$ thermal diffusivity, $\mathrm{m}^{2} / \mathrm{s}$

$\partial \quad$ step limit

$\mu \quad$ dynamic viscosity, $\mathrm{kg} /(\mathrm{m} . \mathrm{s})$

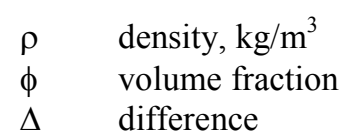

Subscripts

$\begin{array}{ll}\mathrm{c} & \text { channel } \\ \mathrm{f} & \text { fluid } \\ \mathrm{h} & \text { hydraulic } \\ \mathrm{max} & \text { maximum } \\ \text { min } & \text { minimum } \\ \text { opt } & \text { optimum } \\ \mathrm{s} & \text { solid }\end{array}$

\section{INTRODUCTION}

The consequence of compact, sophisticated electronic devices and advances in semiconductor technology is the rising transistor density and switching speed of microprocessors. This however, results in drastic increase in heat flux dissipation which is anticipated to be in the excess of $100 \mathrm{~W} / \mathrm{cm}^{2}$ in the nearest future [1-3]. As the challenge for advanced cooling techniques toughens, microchannels have become of great interest and popular as it yields large heat transfer rates. As far back as 1981, Tuckerman and Pease [4] proposed that single phased microscopic heat exchangers using water as the coolant could achieve power density cooling of up to $1000 \mathrm{~W} / \mathrm{cm}^{2}$ and with experimentation, the cooling water could dissipate a heat flux of about $790 \mathrm{~W} / \mathrm{cm}^{2}$. However, shape and various geometrical parameters such as the aspect ratio of a microchannel have a great influence on the heat transfer 
capabilities of these heat sinks [5]. Wu and Cheng [6] experimentally showed that though the hydraulic diameter of various micro-channels may be the same, their friction factor may differ if their geometrical shapes are different as his experiments showed an increase in friction factor as the aspect ratio of a micro-channel is increased.

In this work, an optimal geometry for a microchannel heat sink is numerically determined, which minimizes the peak wall temperature using mathematical

\section{COMPUTATIONAL MODEL}

Fig. 1 shows the physical model and the computational domain (Fig. 2) for a micro-channel heat sink. The computational domain is an elemental volume selected from a complete micro-channel heat sink. Heat is supplied to a highly conductive silicon substrate with known thermal conductivity from a heating area located at the bottom of the heat sink. The heat is then removed by a fluid flowing through a number of micro-channels. The heat transfer in the elemental volume is a conjugate problem that combines heat conduction in the solid and convective heat transfer in the liquid.

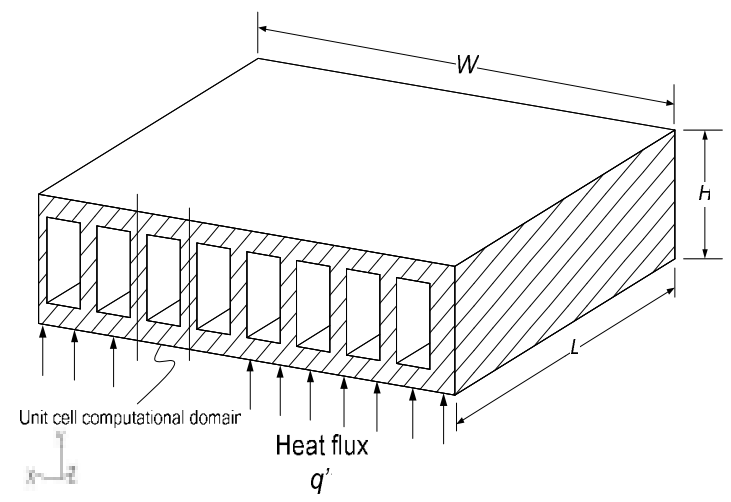

Figure 1. Physical model of a micro-channel heat sink.

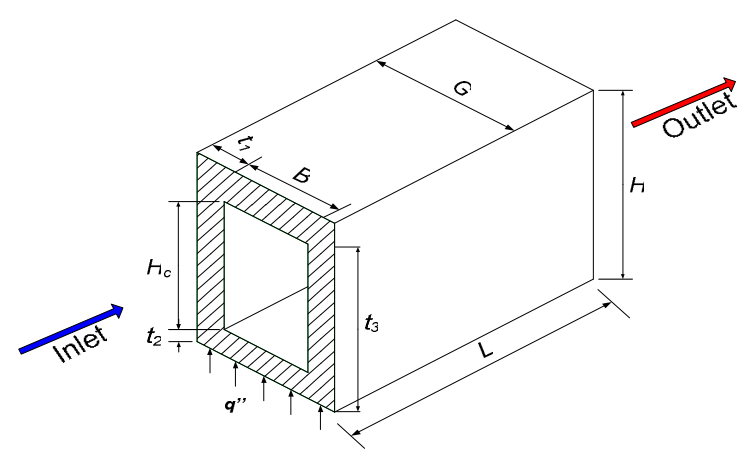

Figure 2. Unit cell computational domain for a micro-channel heat sink.
The following assumptions were made to model the heat transfer and fluid flow in the elemental volume: the hydraulic diameter of the micro-channel under analysis is greater than $10 \mu \mathrm{m}$; for water, the continuum regime applies hence the Navier-Stokes and Fourier equations can still be used to describe the transport processes; steady-state conditions for flow and heat transfer; incompressible flow; the properties of the solid and fluid are constant; and the heat transfer due to radiation and natural convection is negligible. It also assumed that the number of elemental micro-channels is large. The fluids's governing mass, momentum and energy conservation equations which were simplified in accordance with the previously stated assumptions are:

$$
\begin{gathered}
\nabla(\rho \boldsymbol{U})=0 \\
\rho(\boldsymbol{U} \cdot \nabla \boldsymbol{U})+\Delta P-\mu \nabla^{2} \boldsymbol{U}=0 \\
\rho C_{\mathrm{p}}(\boldsymbol{U} \cdot \nabla T)-k_{\mathrm{f}} \nabla^{2} T=0
\end{gathered}
$$

For the solid material, the momentum and energy governing equations are given by eq. (4) and eq. (5).

$$
\begin{gathered}
\boldsymbol{U}=0 \\
k_{\mathrm{s}} \nabla^{2} T=0
\end{gathered}
$$

The bottom wall was supplied with a heat flux of $1 \mathrm{MW} / \mathrm{m}^{2}$ and the coolant (water at $20^{\circ} \mathrm{C}$ ) pumped with a pressure drop ranging from $10 \mathrm{kPa}$ to $60 \mathrm{kPa}$ across the channel length.

FLUENT [7], a finite volume vertex-centred CFD code was used to solve the continuity, momentum and energy equations using the appropriate boundary conditions. A second order upwind scheme was used in discretizing the momentum equation while a SIMPLE algorithm was used for the pressure-velocity coupling. Convergence criteria was set to less than $1 \times 10^{-4}$ for continuity and momentum residuals while the residual of energy was set to less than $1 \times 10^{-7}$.

To ensure accuracy of the results, mesh refinement was performed until a mesh size with negligible changes in thermal resistance was obtained.

\section{MATHEMATICAL OPTIMIZATION}

A robust gradient based optimization algorithm which does not require an explicit line search is used for the mathematical optimization of the conjugate heat transfer problem. The DYNAMIC-Q optimization algorithm applies the dynamic trajectory LFOPC optimization algorithm to successive quadratic approximations of the actual optimization problem [8]. Consider a typical constrained optimization problem of the form: 
$\underset{\text { with respect to } \mathrm{x}}{\operatorname{minimize}} \mathrm{f}(\boldsymbol{x}), \boldsymbol{x}=\left[x_{1}, x_{2}, . x_{l} . ., x_{n}\right]^{T}, x_{l} \in \mathrm{i}^{n}$

subject to the constraints:

$$
\begin{aligned}
& \mathrm{g}_{i}(\boldsymbol{x}) \leq 0, \quad i=1,2, \ldots, m \\
& \mathrm{~h}_{j}(\boldsymbol{x})=0, \quad j=1,2, \ldots, r
\end{aligned}
$$

In this method, successive sub-problems are generated at successive design points $P[k], k=0,1,2, \ldots$ by constructing spherically quadratic approximations which are used to approximate the objective functions or constraints (or both) if they are not analytically given or very expensive to compute numerically $[9,10]$. These spherical quadratic approximations are given by:

$$
\begin{aligned}
& \mathrm{f}(\boldsymbol{x})=\mathrm{f}\left(\boldsymbol{x}^{k}\right)+\nabla^{T} \mathrm{f}\left(\boldsymbol{x}^{k}\right)\left(\boldsymbol{x}-\boldsymbol{x}^{k}\right)+\frac{1}{2}\left(\boldsymbol{x}-\boldsymbol{x}^{k}\right) \mathrm{A}\left(\boldsymbol{x}-\boldsymbol{x}^{k}\right) \\
& g_{i}(x)=\mathrm{g}_{i}\left(\boldsymbol{x}^{k}\right)+\nabla^{T} \mathrm{~g}_{i}\left(\boldsymbol{x}^{k}\right)\left(\boldsymbol{x}-\boldsymbol{x}^{k}\right)+\frac{1}{2}\left(\boldsymbol{x}-\boldsymbol{x}^{k}\right) \mathbf{B}_{i}\left(\boldsymbol{x}-\boldsymbol{x}^{k}\right) \\
& \mathrm{h}_{j}(\boldsymbol{x})=\mathrm{h}_{j}\left(\boldsymbol{x}^{k}\right)+\nabla^{T} \mathrm{~h}_{j}\left(\boldsymbol{x}^{k}\right)\left(\boldsymbol{x}-\boldsymbol{x}^{k}\right)+\frac{1}{2}\left(\boldsymbol{x}-\boldsymbol{x}^{k}\right) \mathbf{C}_{j}\left(\boldsymbol{x}-\boldsymbol{x}^{k}\right)
\end{aligned}
$$

with $\boldsymbol{A}, \boldsymbol{B}_{i}$ and $\boldsymbol{C}_{j}$ being Hessian matrices of the objective, inequality and equality functions respectively. The gradient vector $\nabla^{T} f$ is approximated by means of a forward finite difference scheme as the objective function is obtained numerically from a CFD simulation. The finite differencing scheme used is as follows:

$$
\begin{aligned}
& \frac{\partial \mathrm{f}(\boldsymbol{x})}{\partial x_{l}}=\frac{\mathrm{f}\left(\boldsymbol{x}+\Delta \boldsymbol{x}_{l}\right)-\mathrm{f}(\boldsymbol{x})}{\Delta \boldsymbol{x}_{l}} \forall l=1,2, \ldots, n \\
& \frac{\partial \mathrm{g}_{i}(\boldsymbol{x})}{\partial x_{l}}=\frac{\mathrm{g}_{i}\left(\boldsymbol{x}+\Delta \boldsymbol{x}_{l}\right)-\mathrm{g}_{i}(\boldsymbol{x})}{\Delta \boldsymbol{x}_{l}} \forall i=1,2, \ldots, m \\
& \frac{\partial \mathrm{h}_{j}(\boldsymbol{x})}{\partial x_{l}}=\frac{\mathrm{h}_{j}\left(\boldsymbol{x}+\Delta \boldsymbol{x}_{l}\right)-\mathrm{h}_{j}(\boldsymbol{x})}{\Delta \boldsymbol{x}_{l}} \forall j=1,2, \ldots, r
\end{aligned}
$$

with $\Delta \boldsymbol{x}_{l}=\left[0,0, \ldots, \Delta x_{l}, \ldots 0\right]^{T}$ being an appropriate differencing step size. The constraints gradient vectors on the other hand are provided analytically.

In order to achieve convergence in a stable and controlled form, move limits are used in the DYNAMIC-Q algorithm. The move limit takes on the form of a constraint by limiting the movement of each design variables xlk by not allowing the new design point to move too far away from the current design point. This additional constraint is of the form:

$$
\begin{aligned}
& \boldsymbol{x}_{l}-\boldsymbol{x}_{l}{ }^{k}-\delta_{l} \leq 0 \\
& -\boldsymbol{x}_{l}+\boldsymbol{x}_{l}{ }^{k}-\delta_{l} \leq 0
\end{aligned} ; l=1,2, \ldots, n
$$

The DYNAMIC-Q algorithm terminates when the norm of the step size or function value is less than a specified tolerance.

\section{OPTIMIZATION PROBLEM}

The optimization problem aims to find the best micro-channel heat sink geometric parameters that give the minimum peak temperature for a fixed pressure drop and total volume. The design variables which greatly affect the cooling ability of microchannel heat sinks are the geometric parameters $t_{1}, t_{2}, t_{3}, H$ and $G$ as depicted in Fig. 2.

\section{Constraints}

The optimization problem was carried out subject to the following constraints.

1) Solid Volume Fraction: The solid volume fraction $\phi$ which is the ratio of solid volume material $V_{\mathrm{s}}$ to the total volume $V$ of the micro-channel heat sink. This was allowed to vary between 0.3 and 0.8 .

$$
0.3 \leq\left[\phi=\frac{V_{s}}{V}=\frac{A_{s} L}{A L}=\frac{A_{s}}{A}\right] \leq 0.8
$$

where $A_{\mathrm{s}}$ is the area of the solid material and $A$ the total area of the heat sink.

2) Manufacturing Restraints: Assuming the DRIE manufacturing technique $[11,12]$ was employed in the fabrication of the heat sink, the maximum allowable aspect ratio is 20. Also the minimum allowable thickness of the top and bottom wall is $50 \mu m[13,14]$.

3) Total Fixed Volume: For each optimization problem, the computational volume is kept constant.

$$
\begin{aligned}
& V=G H L=\text { constant } \\
& \text { but } \mathrm{L} \text { is constant at } 10 \mathrm{~mm} \\
& \therefore \frac{V}{L}=A=G H=\text { constant }
\end{aligned}
$$

\section{Optimization Procedure}

The optimization problem presented in previous section was solved by coupling The DYNAMIC-Q optimization algorithm with computational fluid dynamics (FLUENT) and grid generation (GAMBIT [15]) code in a MATLAB [16] environment. Fig. 3 gives a flow guide to how the automation is carried out until convergence (either by step size or function value criteria) is reached. To ensure that the converged solution obtained is indeed the global minimum, a multi starting guess approach is used.

\section{RESULTS AND DISCUSSION}

The optimization problem formulated above is now applied to a given computational volume $\mathrm{V}=$ $0.9 \mathrm{~mm}^{3}$ with a fixed pressure drop varying from 10 $\mathrm{kPa}$ to $60 \mathrm{kPa}$. The five design geometric parameters are then varied to determine the minimum peak 
temperature and the effect of pressure drop on the solid volume fraction, hydraulic diameter, channel aspect ratio and other heat transfer parameters.

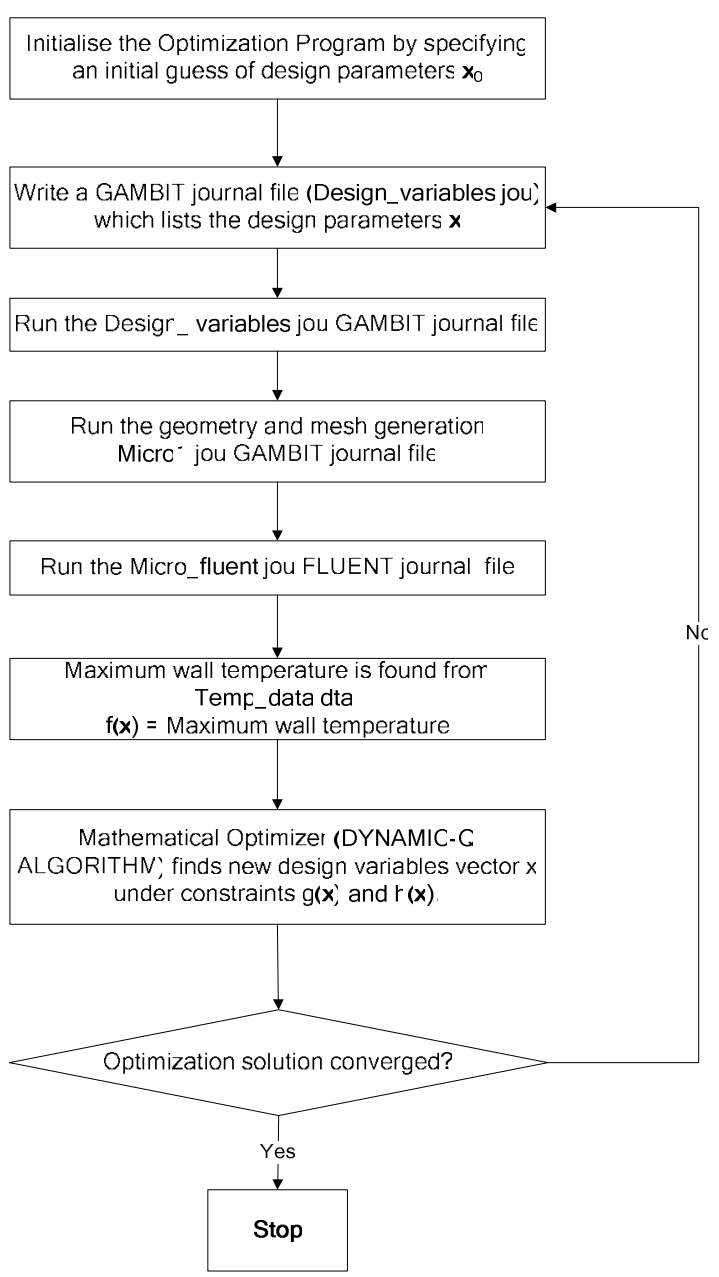

Figure 3. Flow diagram showing the optimization automation process

Fig. 4 shows the effects of the minimized wall peak temperature difference $\Delta \mathrm{T}_{\min }$ of the microchannel with respect to the change in the applied fixed pressure drop. It shows a non-linear decrease in $\Delta \mathrm{T}_{\min }$ because of the increased forced convection heat transfer made possible with the increase in the applied pressure drop across the micro-channel length. The trend is in agreement with already published work in the open literature $[3,13,17]$. This shows that drastic cooling capabilities can be achieved by using adequate pumping power; however a trade-off will always be required.

Fig. 5 shows the effect of pressure drop on the optimal solid volume fraction $\phi_{o p t}$. As the pressure drop increases $\phi_{\text {opt }}$ also increases. An approximate linear relationship exist between $\phi_{\text {opt }}$ and the pressure drop. Fig. 5 also shows that the optimal solid volume fraction ranges between 0.3 and 0.5 which agrees with the results published by BelloOchende et al. [3].

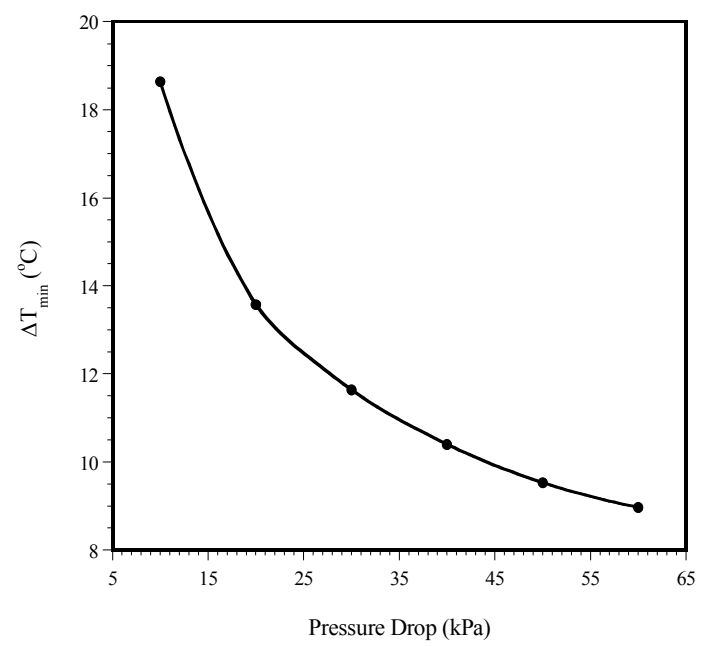

Figure 4. The effect of the change in pressure drop on the optimal wall peak temperature difference.

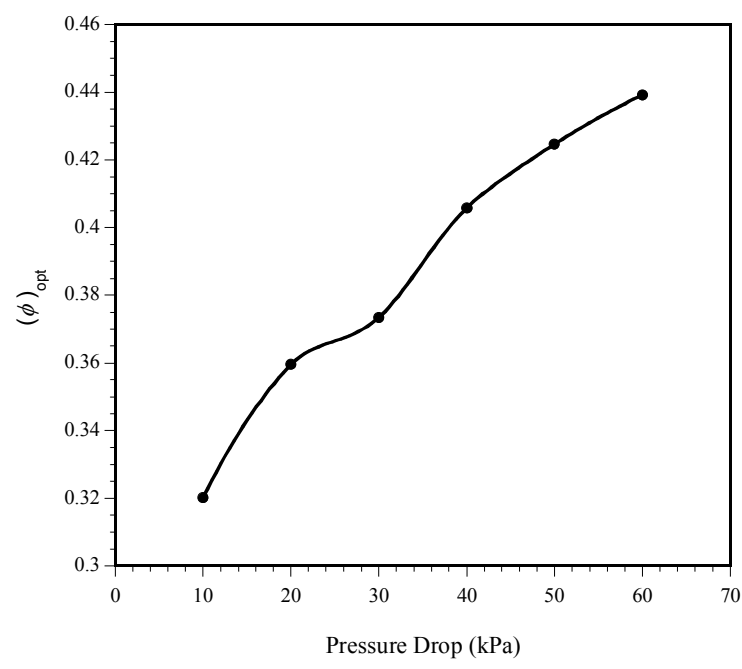

Figure 5. The effect of the change in pressure drop on the optimal solid volume fraction.

As shown in Fig. 6, the optimal aspect ratio of the micro-channel exhibits varying relationship in relation to a change in the applied pressure drop. With an increase in pressure drop, an increase in the optimal aspect ratio is observed up until $35 \mathrm{kPa}$. There is a decrease in the aspect ratio with any further increase in pressure drop. Fig. 7 shows a decrease in the channel hydraulic diameter with an increase in pressure drop. However, this decrease levels out at higher pressure drops.

Fig. 8 shows a direct proportional relationship between the maximised dimensionless global thermal conductance and the dimensionless pressure drop (Bejan number) which is defined as: 


$$
B e=\frac{\Delta P V^{2 / 3}}{\alpha \mu}
$$

The maximized global thermal conductance is expressed as:

$$
C_{\max }=\frac{q^{\prime \prime} L}{k\left(\Delta T_{\max }\right)_{\min }}
$$

This implies that as the pressure drop increases, the heat transfer ability per unit time of the heat sink increases linearly.

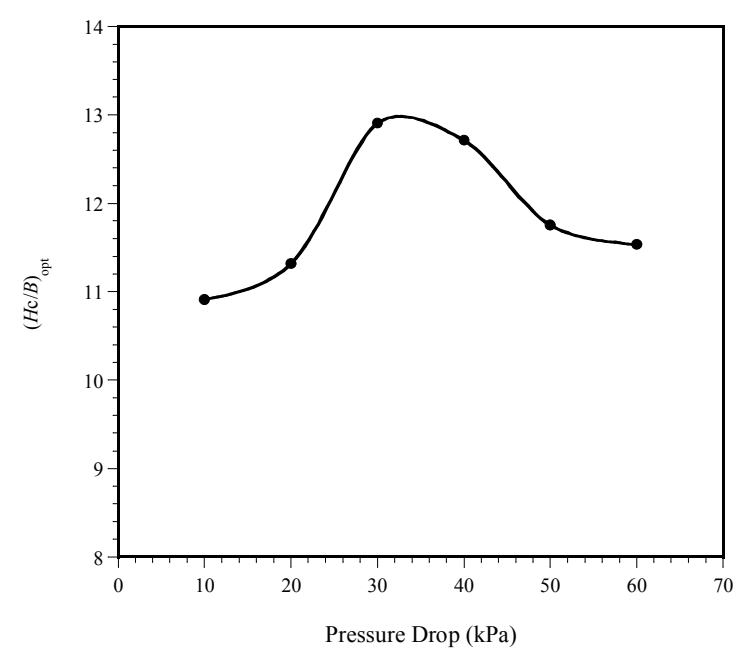

Figure 6. The effect of the change in pressure drop on the optimal channel aspect ratio.

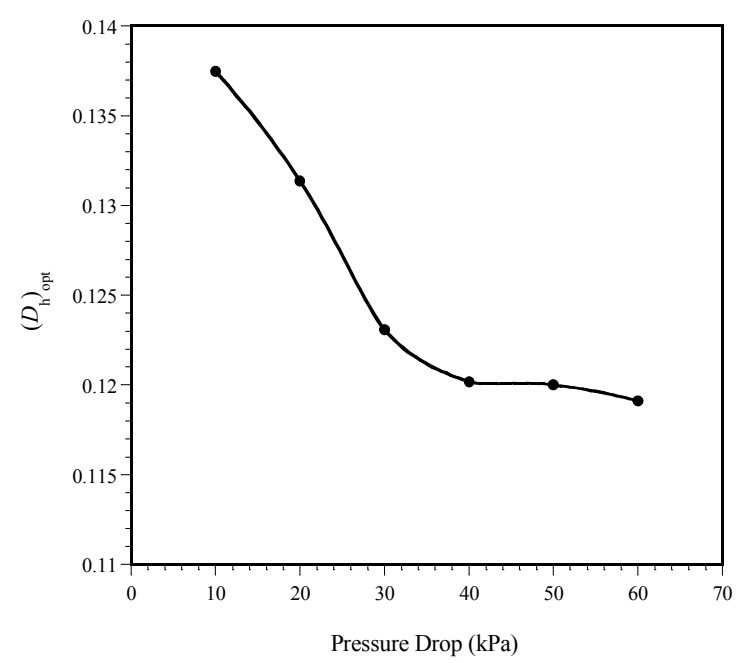

Figure 7. The effect of the change in pressure drop on the optimal channel hydraulic diameter.

The volume constraint was relaxed and then decreased gradually from the initial set volume of $0.9 \mathrm{~mm}^{3}$ to investigate the influence of the computational volume on the heat sink optimal dimensions. Table 1 gives the design results for a range of constant computational volumes when a pressure drop of $50 \mathrm{kPa}$ is applied across the microchannel. These results show a decrease in the minimized wall peak temperature with an increase in the heat sink volume as the heat generated within the volume increases as the heat sink volume is decreased. The table also shows that the optimized volume fraction $\phi_{\text {opt }}$ and hydraulic diameter increases as the volume increases.

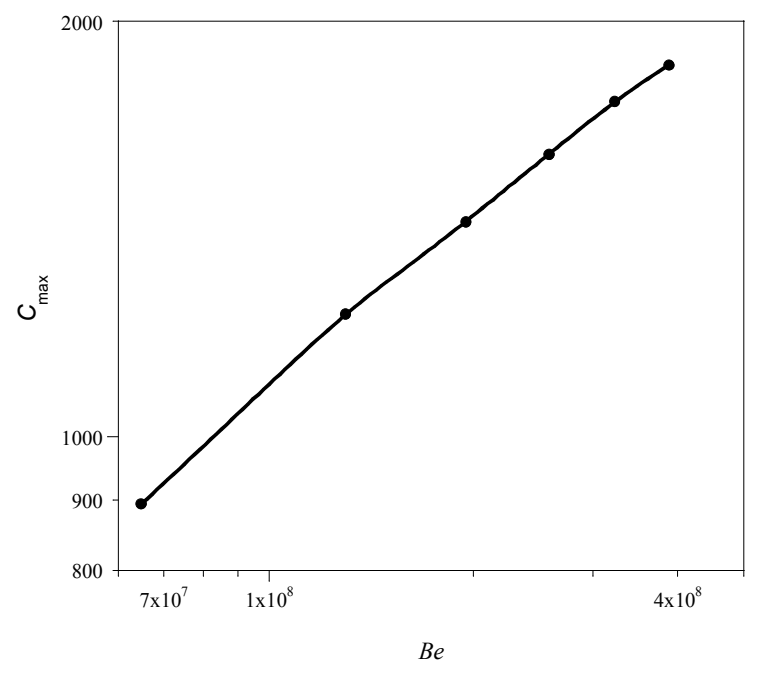

Figure 8 . The effect of the change in pressure drop on the optimal channel hydraulic diameter.

Table 1. Optimal results for different computational volumes

\begin{tabular}{|c|c|c|c|c|}
\hline $\begin{array}{c}\mathrm{V} \\
\left(\mathrm{mm}^{3}\right)\end{array}$ & $\Delta \mathrm{T}_{\min }\left({ }^{\mathrm{C}} \mathrm{C}\right)$ & $\left(\mathrm{H}_{\mathrm{c}} / \mathrm{B}\right)_{\text {opt }}$ & $\phi_{\text {opt }}$ & $\begin{array}{c}\left(\mathrm{D}_{\mathrm{h}}\right)_{\text {opt }} \\
(\mathrm{mm})\end{array}$ \\
\hline 0.9 & 29.53 & 11.752 & 0.425 & 0.122 \\
\hline 0.8 & 29.79 & 10.069 & 0.425 & 0.123 \\
\hline 0.7 & 30.12 & 10.359 & 0.386 & 0.118 \\
\hline
\end{tabular}

Fig. 9 shows the optimal static temperature contour of the heat sink when a pressure difference of $50 \mathrm{kPa}$ is applied along its length and transversely at the exit of the heat sink. The solution of the conjugate heat transfer problem shows a gradual increase in temperature across the channel length from the fluid inlet to its outlet with the hot spot located at the bottom wall. 


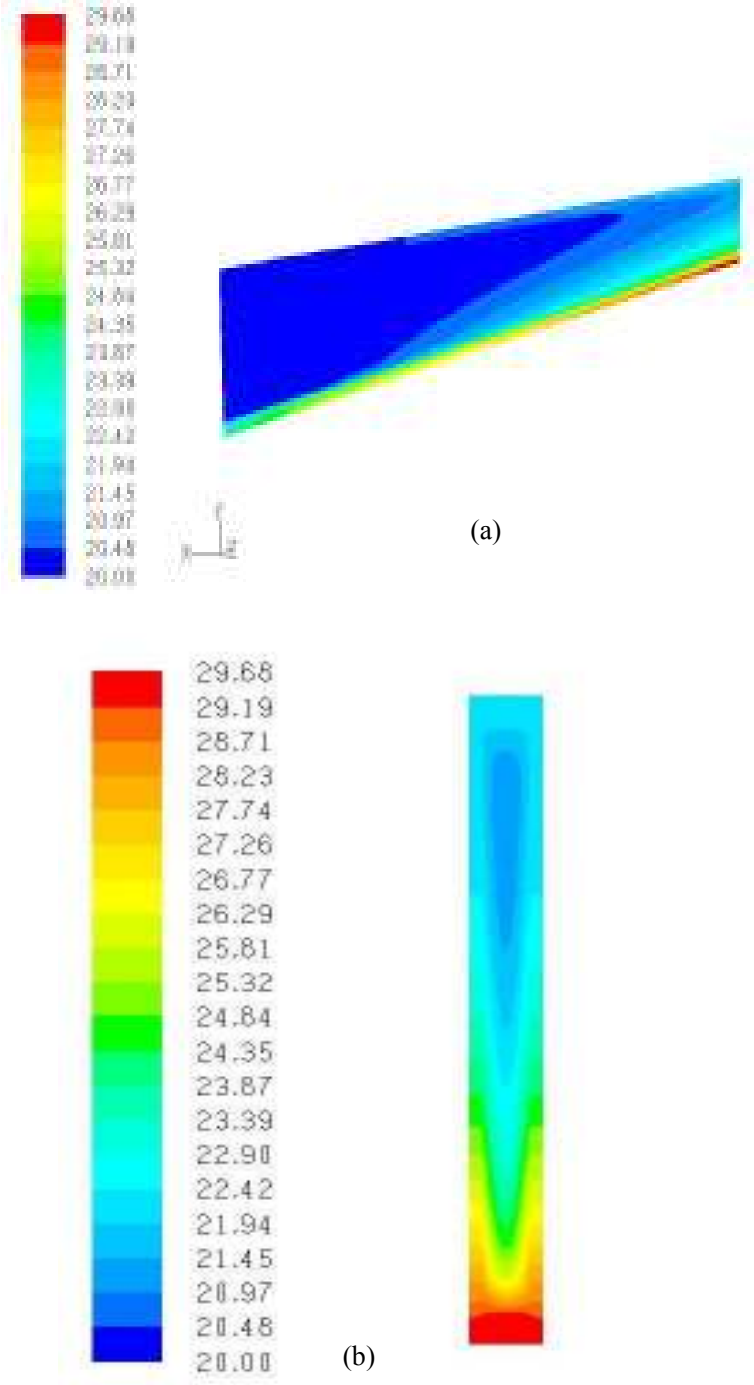

Figure 9. (a) Temperature contours (in ${ }^{\circ} \mathrm{C}$ ) across the length of the heat sink. It shows the gradual increase in temperature along its length. (b) Temperature contours (in ${ }^{\circ} \mathrm{C}$ ) across the transverse axis showing an increase in temperature from the channel top wall to the hot spot bottom wall.

\section{CONCLUSIONS}

In this paper, it has been demonstrated that numerical simulations and mathematical optimization can be used to optimally design micro-channels. For a pressure drop range between $10 \mathrm{kPa}$ and $60 \mathrm{kPa}$, the optimal peak wall temperature decreased exponentially with an increase in pressure. An optimal channel aspect ratio was found to exist between 11 and 13 with a linear increase in the solid volume fraction $\phi$ ranging between 0.3 and 0.5 experienced when the applied pressure drop increases. Further numerical optimization results obtained showed a linear relationship between the dimensionless maximized global thermal conductance $\mathrm{C}_{\max }$ and the dimensionless pressure drop.

\section{ACKNOWLEDGEMENTS}

This work was supported by the Advanced Engineering Centre of Excellence at the University of Pretoria, National Research Foundation (NRF) of South Africa, TESP, EEDSM Hub and the CSIR.

\section{REFERENCES}

Hong, F. J., Cheng, P., Ge, H., and Joo, G. T., 2007, Conjugate Heat Transfer in Fractal-shaped Microchannel Network Heat Sink for Integrated Micoelectronic Cooling Application, International Journal of Heat and Mass Transfer, Vol. 50, pp. 4986-4998.

Toh, K. C., Chen, X. Y., and Chai, J. C., 2002, Numerical Computation of Fluid Flow and Heat Transfer in Microchannels, International Journal of Heat and Mass Transfer, Vol. 45, pp. 5133-5141.

Bello-Ochende, T., Liebenberg, L., and Meyer, J. P., 2007, Constructal Cooling Channels for Microchannel Heat Sinks, International Journal of Heat and Mass Transfer, Vol. 50, pp. 4141-4150.

Tuckerman, D. B., and Pease, R. F. W., 1981, High Performance Heat Sinking for VLSI, IEE Electron Device Letters, EDL-2, pp. 126-129.

$\mathrm{Wu}, \mathrm{H}$. Y., and Cheng, P., 2003, An Experimental Study of Convective Heat Transfer in Silicon Microchannels with Different Surface Conditions, International Journal of Heat and Mass Transfer, Vol. 46, pp. 2547-2556.

$\mathrm{Wu}$, H. Y., and Cheng, P., 2003, Friction Factors in Smooth Trapezoidal Silicon Microchannels with Different Aspect Ratios, International Journal of Heat and Mass Transfer, Vol. 46, pp. 2519-2525.

Fluent Inc., 2001, Fluent Version 6 Manuals, Centerra Resource Park, 10 Cavendish Court, Lebanon, New Hampshire, USA, (www.fluent.com).

Snyman, J. A., 2005, Practical Mathematical Optimization: An Introduction to Basic Optimization Theory and Classical and New Gradient-Based Algorithms, Springer, New York.

Snyman, J. A., and Hay, A. M., 2002, The DYNAMIC-Q Optimization Method: An Alternative to SQP?, Computer and Mathematics with Applications, Vol. 44, pp. 1589-1598.

de Kock, D. J., 2005, Optimal Tundish Methodology in a Continuous Casting Process. PhD Thesis, Department of Mechanical and Aeronautical Engineering, University of Pretoria.

Laermer, F., and Urban, A., 2003, Challenges, Developments and Application of Silicon Deep Reactive Ion Etching, Microelectronic Engineering, Vol. 67-68, pp. 349-355.

Madou, M. J., 2002, MEMS Fabrication, in MEMS Handbook, M. Gad-el-Hak, Ed., Boca Raton, FL: CRC.

Husain, A., and Kim, K., 2008, Shape Optimization of Micro-Channel Heat Sink for Micro- 
Electronic Cooling, IEEE Transactions on Components and Packaging Technologies, Vol. 31, No. 2, pp. 322-330.

Li, J., and Peterson, G. P., 2006, Geometric Optimization of a Micro Heat Sink with Liquid Flow', IEEE Transactions on Components and Packaging Technologies, Vol. 29, No. 1, pp. 145154.

Fluent Inc., 2001, Gambit Version 6 Manuals, Centerra Resource Park, 10 Cavendish Court, Lebanon, New Hampshire, USA, (www.fluent.com).

The MathWorks, Inc., 2008, MATLAB \& Simulink Release Notes for R2008a, 3 Apple Hill Drive, Natick, MA, (www.mathworks.com).

Husain, A., Kim, K., 2008, Multiobjective Optimization of a Microchannel Heat Sink using Evolutionary Algorithm, Journal of Heat Transfer, Vol. 130, pp. 1-3.

Received: September 04, 2008

Revised: October 04, 2008

Accepted: November 04, 2008 